\title{
Exploration of cardiac sympathetic adrenergic nerve activity in narcolepsy
}

Lucie Barateau, MD ${ }^{1-3}$, Régis Lopez, MD, PhD,${ }^{1-3}$ Sofiene Chenini, MD ${ }^{1,2}$ Elisa Evangelista, MD, ${ }^{1-3}$ Meriem Benkiran, MD ${ }^{4}$ Denis Mariano-Goulart, MD, $\mathrm{PhD},{ }^{4,5}$ Isabelle Jaussent, $\mathrm{PhD}^{3}$, Yves Dauvilliers, $\mathrm{MD}, \mathrm{PhD}^{1-3}$

${ }^{1}$ Sleep-Wake Disorders Centre, Department of Neurology, Gui-de-Chauliac Hospital, CHU Montpellier, France

${ }^{2}$ National Reference Network for Narcolepsy, CHU Montpellier, France

${ }^{3}$ INSERM, U1061, Neuropsychiatrie, Recherche Clinique et Epidémiologique, Univ. Montpellier, Montpellier, France

${ }^{4}$ Department of Nuclear Medicine, CHU Montpellier, France

${ }^{5}$ PhyMedExp, University of Montpellier, INSERM, CNRS, France

\section{*Corresponding author:}

Prof. Yves Dauvilliers

National Reference Centre of Narcolepsy and Central Hypersomnia, Inserm U1061

Neurology Department, CHU Gui-de-Chauliac

80, avenue Augustin Fliche

34295 Montpellier Cedex 5, France

Tel.: +33467337478

Fax: +33467337285

E-mail: y-dauvilliers@chu-montpellier.fr 


\section{HIGHLIGHTS}

(1) Orexin has a direct effect on autonomic regulation and narcoleptics exhibit sympathetic dysfunction.

(2) Exploration of cardiac sympathetic adrenergic nerve activity in narcolepsy by MIBG scintigraphy.

(3) Absence of cardiac sympathetic denervation in narcolepsy but association with REM sleep deregulation. 


\section{ABSTRACT}

Objective: To compare cardiac sympathetic adrenergic nerve activity in patients with narcolepsy type 1 (NT1) and controls using ${ }^{123}$ I-MIBG myocardial scintigraphy, and to determine the clinical and neurophysiological variables associated with ${ }^{123}$ I-MIBG scintigraphy results in NT1.

Methods: Fifty-six NT1 patients and 91 controls without neurological diseases underwent a cardiac scintigraphy. MIBG uptake was quantified by delayed heart/mediastinum (H/M) ratio. Clinical, neurophysiological and biological determinants of a low H/M were assessed in NT1.

Results: MIBG uptake did not differ between NT1 and controls in crude and adjusted associations. Five patients had low MIBG uptake ( $<1.42$, first decile of controls), often with advanced age, cardiovascular (CV) diseases, stimulants intake, and REM sleep behavior disorder. Patients with $\mathrm{H} / \mathrm{M}<1.62$ (lowest tertile) were older, with higher BMI, microarousal index and CV comorbidities. A three-fold increase of phasic/tonic REM sleep motor activities was found in those patients, confirmed in a subanalysis of 40 drug-free patients. No association was found with CSF hypocretin levels.

Conclusion: A direct measure of the heart adrenergic nerve activity revealed no sympathetic denervation in NT1.

Significance: Our results indicate normal cardiac sympathetic innervation in NT1. However, few patients with low MIBG uptake also presented CV comorbidities and REM sleep motor deregulation, potentially at high CV risk, requiring a careful follow-up.

Keywords: narcolepsy, orexin/hypocretin, cardiac MIBG scintigraphy, autonomic dysfunction, sympathetic, REM sleep behavior disorder. 


\section{Introduction}

Narcolepsy type 1 (NT1) is an orphan sleep disorder caused by the selective and irreversible loss of hypocretin/orexin neurons that widely project to brain, brainstem and intermediolateral nucleus neurons of the spinal cord, and have key roles in autonomic and cardiovascular $(\mathrm{CV})$ regulation (Dun et al. 2000; Dauvilliers et al. 2007; Grimaldi et al. 2014). Hypocretindeficient mice show lower arterial blood pressure (BP) during wakefulness and blunted nonrapid eye movement (REM) sleep and REM sleep-related BP decreases compared with wild type animals (Bastianini et al. 2011; Lo Martire et al. 2012). Intracerebroventricular administration of hypocretin in rats stimulate arousal and elevate arterial BP, heart rate (HR), and plasma catecholamine levels in a dose-dependent manner (Samson et al. 1999; Shirasaka et al. 1999). These results seem to be mainly mediated by the activation of sympathetic preganglionic neurons in the spinal cord and the consequent increase of the sympathetic outflow (Antunes et al. 2001).

Several clinical autonomic dysfunctions have been described in patients with NT1, such as pupillary abnormalities, non-dipper BP profile, metabolic and heart rate variability alterations (Plazzi et al. 2011; Dauvilliers et al. 2012). The underlying mechanisms remain unclear with conflicting results in drug-naive patients with NT1 during wakefulness. Some studies found an increased sympathetic activation (Grimaldi et al. 2010, 2012), whereas a recent study revealed a decreased sympathetic tone in drug-free narcoleptic patients (Donadio et al. 2014), a result more in line with preclinical findings. However, these studies in patients with NT1 focused on the peripheral sympathetic outflow only, with no direct assessment of the cardiac sympathetic function.

Meta-iodobenzylguanidine (MIBG, a physiological norepinephrine analogue) cardiac scintigraphy is a reliable method for the objective evaluation of cardiac adrenergic nerve activity. This sensitive test assesses norepinephrine presynaptic neuronal uptake and the 
integrity of myocardial presynaptic nerve terminals (Sisson et al. 1987; Gill et al. 1993). A reduced delayed heart to mediastinum $(\mathrm{H} / \mathrm{M})$ ratio reflects a cardiac sympathetic dysfunction (Yamashina and Yamazaki 2007).

In the present study, we aimed to explore the cardiac sympathetic adrenergic nerve activity in NT1 by comparing the delayed H/M ratio calculated after ${ }^{123}$ I-MIBG myocardial scintigraphy in patients with NT1 and control subjects, and assessing clinical and neurophysiological determinants of ${ }^{123}$ I-MIBG scintigraphy results in NT1.

\section{Methods}

\subsection{Participants}

Fifty-six patients with NT1 (38 men, median age 38.5 years, range 13-86) were recruited at the National Reference Centre for Narcolepsy of Montpellier, France. The diagnosis of NT1 was confirmed according to the ICSD-3 criteria (AASM: American Academy of Sleep Medicine 2014): mean sleep latency $<8$ minutes on the multiple sleep latency test (MSLT), $\geq 2$ sleep onset REM periods (SOREMPs), and definite cataplexy. All patients were positive for HLA DQB1*06:02 typing. Lumbar puncture was performed in 43 patients (76.8\%), and all had low cerebrospinal fluid (CSF) hypocretin-1 level (<110 pg/ml).

Ninety-one control subjects (42 men, median age 53 years, range 10-87) were selected from the local control database of the Department of Nuclear Medicine of Montpellier Hospital to determine the normal values of the MIBG uptake parameters. This methodology is often used in MIBG scintigraphy studies as pathological cardiac MIBG values often differed between centers in the literature, depending on the involved populations, but mostly on the acquisition and processing conditions (Yamada et al. 2003; Yamashina and Yamazaki 2007). Those subjects had no neurological or sleep disorders, no heart failure, no diabetes mellitus, no drugs

that may affect the results of MIBG myocardial scintigraphy. They often underwent ${ }^{123} \mathrm{I}-$ 
MIBG cardiac scintigraphy for another reason, mostly to exclude a pheochromocytoma. Only age, gender and body mass index (BMI) were available in those subjects.

This study was approved by the institutional review boards of Montpellier University, France. The study protocol was designed and performed in accordance with the approved guidelines. Informed consent was obtained from all subjects.

\subsection{Clinical and cardiovascular evaluation}

Age at NT1 onset, disease duration, severity of excessive daytime sleepiness (EDS), and presence of REM sleep behaviour disorder (RBD) were determined using a standardized clinical interview. Comorbid RBD in patients with NT1 was defined as the presence of motor behaviours associated with dreaming, occurring during the REM sleep, and the videopolysomnography (PSG) confirmation of REM sleep without atonia (AASM: American Academy of Sleep Medicine 2014). Patients with NT1 underwent a physical examination with measurement of BMI. Comorbid CV and metabolic disorders were assessed, and defined as: (1) CV disorders (e.g., coronary artery disease, chronic heart failure, arrhythmia or stroke), (2) hypertension (systolic $\mathrm{BP} \geq 140 \mathrm{mmHg}$ and diastolic $\mathrm{BP} \geq 90 \mathrm{mmHg}$ ) and/or treatment with antihypertensive drugs, (3) medical history of diabetes mellitus and/or use of antidiabetic drugs, and (4) dyslipidaemia and/or use of lipid-lowering drugs. Metabolic syndrome was diagnosed according to the National Cholesterol Education Program Adult Treatment Panel

III criteria (Lorenzo et al. 2007). Regular tobacco and alcohol consumption, and physical inactivity were reported. Ambulatory BP was monitored for 24 hours in all patients with NT1 to determine the mean systolic and diastolic BP and heart rate (HR) over 24-hour, during daytime (from $7 \mathrm{am}$ to $11 \mathrm{pm}$ ) and during night-time (from $11 \mathrm{pm}$ to $7 \mathrm{am}$ ).

\subsection{Polysomnographic evaluation}


All drug-free patients with NT1 underwent one night video-PSG recording in the sleep laboratory. Sleep stages, micro-arousals, periodic limb movements during sleep (PLMS) and apnoea-hypopnea index (AHI) were manually scored, according to standard criteria (Iber C, Ancoli-Israel S, Chesson A, Quan S, for the American Academy of Sleep Medicine 2007). REM sleep was scored without the chin electromyographic (EMG) criterion allowing for the maintenance of muscle tone during REM sleep. A 30-second-epoch of REM sleep was defined as tonic, if tonic chin EMG activity was present for $\geq 50 \%$ of the epoch. Phasic EMG activity was scored from the chin EMG recording and represented the percentage of 2-second mini-epochs of REM sleep containing phasic EMG events, defined as any burst of muscle activity lasting from 0.3 to 5 seconds with amplitude that exceeded four times the baseline EMG signal. REM sleep without atonia was defined as the presence of a tonic REM EMG activity that exceeded $30 \%$ of the total REM sleep duration. Phasic EMG activity was considered abnormal when higher than 15\% (Montplaisir et al. 2010).

\subsection{Cardiac scintigraphy}

All participants underwent ${ }^{123}$ I-MIBG cardiac scintigraphy. Images were acquired 3 hours (delayed phase) after intravenous injection of $185 \mathrm{MBq}{ }^{123} \mathrm{I}-\mathrm{MIBG}$ using a General Electric INFINIA Hawkeye 4 gamma camera (GE Healthcare, Tirat Carmel, Israel) with low energy and high resolution collimators. Cardiac ${ }^{123}$ I-MIBG uptake was assessed on planar images. For this purpose, rectangular regions of interest (ROI) of $7 \times 7$ pixels were drawn on the heart

(H) and mediastinum (M) in each planar image (Flotats et al. 2010). Cardiac ${ }^{123}$ I-MIBG uptake was assessed by calculating the delayed $\mathrm{H} / \mathrm{M}$ activity ratio, the most reliable MIBG biomarker, taking the average count per pixel in the ROI. Scintigraphic data were analysed by nuclear medicine specialists, blinded to the subject' status. 
At the time of scintigraphy, 16 patients with NT1 were treated (14 patients with stimulants and anticataplectic drugs and two with a stimulant alone), 22 patients had stopped psychostimulant medications $\geq 2$ weeks prior to the evaluation, and 18 patients were drugnaive. The median delay between cardiac scintigraphy and video-PSG recording was one day.

\subsection{Statistical analysis}

Categorical variables are presented as percentages, and quantitative variables as medians with ranges (distributions tested with the Shapiro-Wilk test were mostly skewed). Associations between demographic and clinical characteristics and the two groups (controls and patients with NT1) were analysed using logistic regression models. Variables associated with NT1 at $\mathrm{p} \leq 0.10$ in the univariate regression models were included in multivariate logistic models to estimate the adjusted association between delayed H/M ratio and the two groups. To assess the determinants of cardiac sympathetic dysfunction in NT1, patients were divided into two groups, those with a delayed H/M ratio $<1.62$ (considered as patients with a low delayed H/M ratio) and those with a delayed $\mathrm{H} / \mathrm{M}$ ratio $\geq 1.62$ (considered as patients with a high delayed $\mathrm{H} / \mathrm{M}$ ratio). The cut-off of 1.62 corresponded to lowest tertile of the delayed $\mathrm{H} / \mathrm{M}$ ratio in NT1 patients. Comparisons between a low and high delayed $\mathrm{H} / \mathrm{M}$ ratio were studied using logistic regression models. However, due to the small number of outcome events per independent variable, the results were only adjusted for age, because the fitted regression model was not accurate when adjusted for two covariates or more. Non-parametric tests (Mann Whitney U Test or Fisher's exact test, according to the type of variables) were used to compare drug-free (at scintigraphy) patients with low and with high (the other two tertiles) delayed H/M ratio. Spearman's rank order correlations were used to determine associations between two continuous variables. The significance level was set at $\mathrm{p}<0.05$. Analyses were performed with SAS (version 9.4; SAS Inc., Cary, North Carolina). 


\section{Results}

\subsection{Clinical characteristics and PSG results}

Among the 56 patients with NT1, $19.6 \%$ were obese, $51.8 \%$ overweight, and $8.9 \%$ met the criteria for metabolic syndrome. Twenty-five patients (44.6\%) had at least one comorbid CV disease. Among them, $15(60 \%)$ had hypertension (including 11 with antihypertensive medication), 17 (68\%) dyslipidaemia (including five with lipid-lowering drugs), one (4\%) type 2 diabetes (with antidiabetic treatment), and 9 (36\%) a cardiac disorder (two with mild myocardial infarction, one with chronic heart failure, one with stable angina, and five with arrhythmia). Twenty-three patients with NT1 (41\%) showed a non-dipping BP pattern, defined as a fall of the nocturnal BP lower than $10 \%$ relative to the daytime BP (Hansen et al. 2005). Eleven patients (19.6\%) had moderate (AHI between 15 and 30/hour) and eight (14.3\%) severe (AHI $\geq 30 /$ hour) sleep apnoea syndrome. Finally, 34 patients with NT1 $(60.7 \%)$ had clinically defined RBD. Among the controls $(n=91), 17.5 \%$ were obese.

Compared with patients with NT1, controls were older and more frequently women. Therefore, the subsequent analyses were adjusted for age and sex, and also for BMI that tended to be higher in the NT1 group than in control group ( $\mathrm{p}=0.1)$ (Table 1).

\subsection{Cardiac MIBG uptake in patients with NT1 and controls}

The delayed H/M ratio (taking as a continuous variable or as a categorical variable) did not differ between patients with NT1 and controls in crude and adjusted analyses (Table 1). Similar results were obtained when comparing only patients with NT1 and age- and sexmatched controls ( $n=48 /$ group), or the subgroup of patients with NT1 not taking any drug at the time of scintigraphy ( $\mathrm{n}=40)$ with controls (data not shown). 
As no pathological $\mathrm{H} / \mathrm{M}$ ratio values were validated, we decided to choose the first decile of the $\mathrm{H} / \mathrm{M}$ ratio from our local control group (1.42) to define low threshold values. Using this cut-off, only five patients with NT1 $(8.9 \%$, among whom four were men; median age 77 years [range 56-84]; median BMI $28.3 \mathrm{~kg} / \mathrm{m}^{2}$ [25.7-47.8]) had low MIBG uptake (median delayed $\mathrm{H} / \mathrm{M}$ ratio $=1.28$ [1.20-1.33]). Among these five patients, three were above 75 year old, four were treated with psychostimulant and anticataplectic drugs, four had at least one comorbid $\mathrm{CV}$ disease and three had a non-dipping BP profile. Moreover, four of these patients had clinically-defined RBD and three of them met the criteria for REM sleep without atonia.

\subsection{Determinants of low MIBG uptake in patients with NT1}

Patients with NT1 and delayed H/M ratio <1.62 (i.e., the lowest tertile) were older, with higher BMI, higher treatment intake for NT1 and more CV comorbidities than those with $\mathrm{H} / \mathrm{M}$ ratio in the other two tertiles. Delayed H/M ratio was negatively correlated with age $(\mathrm{R}=-0.48, \mathrm{p}=0.0002)$ and with duration of evolution of NT1 $(\mathrm{R}=-0.40, \mathrm{p}=0.002)$. No association was found between H/M ratio and mean CSF hypocretin-1 level. Moreover, the $\mathrm{H} / \mathrm{M}$ ratio was not significantly different between patients with detectable $(\geq 10 \mathrm{pg} / \mathrm{mL})$ and undetectable $(<10 \mathrm{pg} / \mathrm{mL})$ CSF hypocretin-1 levels ( $\mathrm{n}=25$ vs $\mathrm{n}=18$ respectively). Delayed H/M ratio $<1.62$ was associated with higher microarousal index (unadjusted analyses and also after adjustment for age), and with sleep efficiency, AHI and mean 24-hour, daytime, and nighttime systolic, and diastolic BP and HR values (only in unadjusted analyses) (Table 2), but not with the non-dipping blood-pressure profile.

Clinically-defined RBD was not associated with cardiac MIBG uptake. Conversely, patients with delayed H/M ratio <1.62 had three-fold higher phasic or tonic REM sleep EMG activities than those with $\mathrm{H} / \mathrm{M}$ ratio $\geq 1.62$; however this difference remains significant in unadjusted analyses only. Similarly, patients with NT1 and REM sleep without atonia (i.e., 
with $\geq 30 \%$ tonic or $\geq 15 \%$ phasic REM sleep EMG activities) had lower cardiac MIBG uptake than those with preserved REM sleep atonia (delayed H/M ratio: $1.61 \pm 0.24$ vs $1.80 \pm 0.25$, $p=0.029)$. We further compared diagnostic performance of cardiac MIBG uptake using ROC analysis to discriminate patients with REM sleep without atonia (i.e. phasic $\geq 15 \%$ and/or tonic EMG activity $\geq 30 \%$ ). The best cut-off value of delayed $\mathrm{H} / \mathrm{M}$ ratio to discriminate patients with NT1 and REM sleep without atonia was 1.60, according to the Youden Index (area under the curve: $0.70,95 \% \mathrm{CI}=[0.52-0.88]$ ) with a specificity of $77.27 \%$ and a sensitivity of $58.33 \%$. This value of 1.60 is closed to the threshold of 1.62 (i.e. the lowest tertile of the delayed $\mathrm{H} / \mathrm{M}$ ratio in NT1), and none of NT1 patients had a delayed H/M ratio between 1.60 and 1.62. The delayed H/M ratio was also negatively correlated with tonic EMG activity in REM sleep in the NT1 population ( $\mathrm{r}=-0.35, \mathrm{p}=0.008)$. Finally, no association was found between microarousal index in REM sleep and delayed H/M ratio.

\subsection{Determinants of low MIBG uptake in drug-free patients with NT1}

As the unadjusted analyses revealed that treatment of NT1 (i.e. stimulant and anticataplectic drug) at the time of scintigraphy had a significant effect on the cardiac MIBG uptake (Table 2), additional analyses were performed exclusively in the 40 drug-free patients with NT1. In this subgroup, the frequency of $\mathrm{CV}$ comorbidities and the microarousal index were higher patients with $\mathrm{H} / \mathrm{M}$ ratio $<1.62$ than in those with $\mathrm{H} / \mathrm{M}$ ratio $\geq 1.62$, with a similar trend for

BMI (Table 3). Moreover, in drug-free patients with $\mathrm{H} / \mathrm{M}$ ratio $<1.62$, tonic and phasic EMG activities in REM sleep were significantly increased $(\mathrm{p}=0.007$ and $\mathrm{p}=0.008)$. Three $(37.5 \%)$ patients with low H/M ratio values had REM sleep without atonia compared with only two $(6.2 \%)$ in the $\mathrm{H} / \mathrm{M}$ ratio $\geq 1.62$ group.

\section{Discussion}


This study compared the cardiac sympathetic adrenergic nerve activity using ${ }^{123}$ I-MIBG myocardial scintigraphy in a population of well-characterized (drug-free and treated) adults and children with NT1 and in a local clinical control group composed of subjects without cardiac or neurological disorders but who have completed this exam mostly to exclude a pheochromocytoma. Cardiac MIBG uptake was not significantly different between patients with NT1 and controls in crude associations and also after taking into account some potential confounders (age, sex and BMI). Our results indicate that overall, the cardiac sympathetic innervation is not impaired in patients with NT1, in broad agreement with preclinical findings obtained in hypocretin-deficient mice showing no structural evidence of myocardial damage in middle-aged narcoleptic mice, but without quantification of cardiac sympathetic innervation (Silvani et al. 2014).

NT1 is frequently comorbid with sleep fragmentation and CV risk factors, such as obesity, diabetes mellitus, metabolic syndrome, sleep apnoea syndrome, and non-dipping BP profile (Dauvilliers et al. 2012; Jennum et al. 2013; Ohayon 2013). Patients with NT1 also need lifelong treatments with psychostimulants that may affect the autonomic nervous system, leading to increased BP and HR and higher long-term risk of CV diseases (Bosco et al. 2018). However, the incidence of CV disease morbidity and mortality remains uncertain in NT1 and difficult to assess prospectively because of NT1 low prevalence and the frequent young age at onset. Therefore, we decided to assess the clinical and neurophysiological determinants of low ${ }^{123}$ I-MIBG uptake in untreated and treated patients with NT1. ${ }^{123}$ I-MIBG myocardial scintigraphy is a validated sensitive technique to assess the function of myocardial postganglionic presynaptic sympathetic nerve endings, and to predict impaired cardiac sympathetic innervation, heart failure, sudden cardiac death and arrhythmic disorders (Nakata et al. 1998) (Merlet et al. 1992). We found that reduced delayed H/M ratio values were associated with CV disorders, and also with obesity, in agreement with previous studies in 
non-narcoleptic obese subjects (Grassi et al. 1995). We also detected an association between $\mathrm{H} / \mathrm{M}$ ratio $<1.62$ and microarousal index, even after adjustment for age, in the whole patient population and also in the subgroup of drug-free patients. The threshold to define pathological cardiac MIBG values is challenging, with several cutoffs proposed between centres in the literature, from 1.4 to 2.8 , with differences related to the involved populations, sample size, but especially to the procedure and scanning methods (i.e., the different camera-collimator combinations) (Yamashina and Yamazaki 2007). Due to the absence of standardized normative cardiac MIBG values, we used the last decile of the $\mathrm{H} / \mathrm{M}$ ratio in our local control group ( $\mathrm{n}=91$ subjects) to define the threshold of low values (1.42). Using this value, only five patients with NT1 had low MIBG uptake. These five patients were old (median age 77 years), had frequent comorbid CV disorders and RBD, as well as high stimulants intake, and thus they underwent a very close clinical follow-up. Remarkably, one of them developed atrial fibrillation one year after this cardiac evaluation.

Previous studies on the autonomic control in NT1 led to contradictory results (increased, decreased or normal sympathovagal balance during sleep and wakefulness) (CalandraBuonaura et al. 2016). Hypocretin neurons project widely to brain areas that modulate the autonomic nervous system; however hypocretin deficiency might not have an exclusive role in the autonomic dysfunction in NT1, with several studies reporting discordant results (Grimaldi et al. 2010, 2012; Donadio et al. 2014). Our scintigraphy results (no differences between patients with NT1 and controls, and no association between delayed H/M ratio and CSF hypocretin-1 levels) favour the hypothesis of the absence of a direct effect of the hypocretin system on the cardiac adrenergic nerve activity. Several studies in patients with NT1 suggest an enhanced sympathetic activity with a blunted decrease of nocturnal BP (Grimaldi et al. 2010; Dauvilliers et al. 2012). In contrast, a previous study found a decreased sympathetic tone in patients with NT1 (Donadio et al. 2014), in line with the findings 
obtained with most of the orexin-knockout or orexin neuron-depleted mouse models of narcolepsy (Kayaba et al. 2003; Bastianini et al. 2011)(Zhang et al. 2006). However, in this study (Donadio et al. 2014) the sympathetic activity was recorded by microneurography, an intraneural technique that selectively quantifies the peripheral sympathetic outflow. Conversely, we measured in the present study the cardiac adrenergic nerve activity.

The state-dependent sympathetic-parasympathetic regulation of the cardiovascular autonomic system could be a key issue in NT1. Previous studies found attenuated HR responses to leg movements in NREM sleep in patients with NT1, suggesting a reduced sympathetic response (Dauvilliers et al. 2011)'(Sorensen et al. 2013). Other works on patients with NT1 reported higher systolic BP specifically in REM sleep (Grimaldi et al. 2012), and an association between non-dipping profile and higher percentage of REM sleep (Dauvilliers et al. 2012). Here, we found that tonic and phasic EMG activities during REM sleep were increased in patients with delayed $\mathrm{H} / \mathrm{M}$ ratio $<1.62$ during wakefulness, a result confirmed in the analysis focused on drug-free patients. The delayed H/M ratio was also negatively correlated with tonic EMG activity in REM sleep the NT1 population.

However, we did not detect any association between MIBG uptake and clinical RBD in patients with NT1. This is in agreement with a recent study showing lower delayed H/M ratio in patients with idiopathic RBD than in patients with NT1 and comorbid RBD (Barateau et al. 2018). Altogether, the mechanisms underlying the autonomic dysfunctions in NT1 appear complex. Hypocretin deficiency may be involved in the regulation of the cardiovascular autonomic dysfunction and REM sleep deregulation. In our study, only few patients with NT1 had low MIBG values, non-dipping BP patterns, dissociated REM sleep features, and clinical RBD, although almost all of them were hypocretin-deficient.

This study has some strengths. We used myocardial scintigraphy, a very sensitive technique to assess the cardiac adrenergic nerve activity, in a well-defined population of patients with 
NT1, a rare disease. The study was conducted in a single centre to limit potential recruitment and procedure biases. We took into account a large number of potential confounders, including socio-demographic features, lifestyle, CV comorbidities, 24-hour ambulatory BP monitoring, and objective sleep parameters.

This study also has some limitations. The control population used to determine the normal values for MIBG parameters was not a healthy population, a methodology often used in MIBG studies, as this examination is invasive (Fröhlich et al. 2010)(Miyamoto et al. 2006). We cannot provide more clinical details for this control group, as data came from an anonymized database that generates normative values, based on our local acquisition and processing conditions. The MIBG scintigraphy results of some patients ( $n=34$, all NT1 patients with comorbid RBD) and controls $(n=78)$ were reported in a previous article, with a different rationale and methodology focusing on RBD only (Barateau et al. 2018). In this previous study, we found MIBG cardiac uptake difference between patients with NT1-RBD and $\mathrm{iRBD}$, a result supporting the hypothesis of different processes involved in RBD pathogenesis. We also found that early $\mathrm{H} / \mathrm{M}$ ratio and washout rate, other MIBG indices of interest but not available here for controls, were correlated with delayed H/M ratio $(\mathrm{r}=0.89$, $\mathrm{p}<0.0001 ; \mathrm{r}=-0.45, \mathrm{p}=0.0083$ respectively) in patients with NT1 (Barateau et al. 2018), the latter being the best MIBG biomarker to discriminate the groups and the most reliable in according to the literature (Imamura et al. 1996; Nakajima et al. 2018).

The relative low sample size, the frequent comorbidities and intake of drugs for NT1 could have affected the MIBG uptake results. However, we also analysed a subgroup of drug-free NT1 patients and the results remained unchanged. Finally, we did not assess for clinical autonomic manifestations, cardiac autonomic regulation such as the heart rate variability analysis, and for circulating norepinephrine concentrations. 


\section{Conclusions}

To conclude, by using a direct measure of the heart adrenergic nerve activity, we show the absence of global cardiac sympathetic denervation in NT1. However, few patients with NT1 had low MIBG uptake, with comorbidities and REM sleep motor deregulation, potentially at high risk for $\mathrm{CV}$ disease morbidity and mortality, thus requiring a careful clinical follow-up. Further studies are needed to better understand the complex deregulation of the autonomic nervous system in NT1, with reliable CV markers of the sympathovagal balance during wakefulness and REM sleep. 


\section{Disclosure Statement}

Financial disclosure: Prof. Dauvilliers has received funds for speaking, board engagements and travel to conferences by UCB pharma, Jazz, Harmony Biosciences, Takeda, Idorsia, Avadel and Bioprojet. Dr. Lopez has received funds for speaking, and travel to conferences by UCB pharma, Shire and HAC Pharma.

Non-financial disclosure: none. 


\section{References}

AASM: American Academy of Sleep Medicine. ICSD-3: International Classification of Sleep Disorders, 3rd ed. American Academy of Sleep Medicine. 2014.

Antunes VR, Brailoiu GC, Kwok EH, Scruggs P, Dun NJ. Orexins/hypocretins excite rat sympathetic preganglionic neurons in vivo and in vitro. Am J Physiol Regul Integr Comp Physiol. 2001; 281:R1801-1807.

Barateau L, Jaussent I, Lopez R, Evangelista E, Chenini S, Benkiran M, et al. Cardiac sympathetic activity differentiates Idiopathic and symptomatic Rapid Eye Movement Sleep disorder. Sci Rep. 2018; 8:7304.

Bastianini S, Silvani A, Berteotti C, Elghozi J-L, Franzini C, Lenzi P, et al. Sleep related changes in blood pressure in hypocretin-deficient narcoleptic mice. Sleep. 2011; 34:213-8.

Bosco A, Lopez R, Barateau L, Chenini S, Pesenti C, Pépin J-L, et al. Effect of psychostimulants on blood pressure profile and endothelial function in narcolepsy.

Neurology. 2018;10-1212.

Calandra-Buonaura G, Provini F, Guaraldi P, Plazzi G, Cortelli P. Cardiovascular autonomic dysfunctions and sleep disorders. Sleep Med Rev. 2016 ; 26:43-56.

Dauvilliers Y, Arnulf I, Mignot E. Narcolepsy with cataplexy. Lancet. 2007; 369:499-511.

Dauvilliers Y, Jaussent I, Krams B, Scholz S, Lado S, Levy P, et al. Non-dipping blood pressure profile in narcolepsy with cataplexy. PloS One. 2012;7:e38977.

Dauvilliers Y, Pennestri M-H, Whittom S, Lanfranchi PA, Montplaisir JY. Autonomic response to periodic leg movements during sleep in narcolepsy-cataplexy. Sleep.

2011;34:219-23.

Donadio V, Liguori R, Vandi S, Pizza F, Dauvilliers Y, Leta V, et al. Lower wake resting sympathetic and cardiovascular activities in narcolepsy with cataplexy. Neurology.

2014;83:1080-6.

Dun NJ, Le Dun S, Chen CT, Hwang LL, Kwok EH, Chang JK. Orexins: a role in medullary sympathetic outflow. Regul Pept. 2000;96:65-70.

Flotats A, Carrió I, Agostini D, Le Guludec D, Marcassa C, Schäfers M, et al. Proposal for standardization of 123I-metaiodobenzylguanidine (MIBG) cardiac sympathetic imaging by the EANM Cardiovascular Committee and the European Council of Nuclear Cardiology. Eur J Nucl Med Mol Imaging. $2010 ; 37: 1802-12$.

Fröhlich I, Pilloy W, Vaillant M, Diederich NJ. Myocardial MIBG scintigraphy: a useful clinical tool? : A retrospective study in 50 parkinsonian patients. Neurol Sci Off J Ital Neurol Soc Ital Soc Clin Neurophysiol. 2010;31:403-6.

Gill JS, Hunter GJ, Gane G, Camm AJ. Heterogeneity of the human myocardial sympathetic innervation: in vivo demonstration by iodine 123-labeled meta-iodobenzylguanidine scintigraphy. Am Heart J. 1993;126:390-398.

Grassi G, Seravalle G, Cattaneo BM, Bolla GB, Lanfranchi A, Colombo M, et al. Sympathetic activation in obese normotensive subjects. Hypertension. 1995;25:560-563.

Grimaldi D, Calandra-Buonaura G, Provini F, Agati P, Pierangeli G, Franceschini C, et al. Abnormal sleep-cardiovascular system interaction in narcolepsy with cataplexy: effects of hypocretin deficiency in humans. Sleep. 2012;35:519-28.

Grimaldi D, Pierangeli G, Barletta G, Terlizzi R, Plazzi G, Cevoli S, et al. Spectral analysis of 
heart rate variability reveals an enhanced sympathetic activity in narcolepsy with cataplexy. Clin Neurophysiol Off J Int Fed Clin Neurophysiol. 2010;121:1142-7.

Grimaldi D, Silvani A, Benarroch EE, Cortelli P. Orexin/hypocretin system and autonomic control: new insights and clinical correlations. Neurology. 2014;82:271-8.

Hansen TW, Jeppesen J, Rasmussen S, Ibsen H, Torp-Pedersen C. Ambulatory blood pressure and mortality: a population-based study. Hypertension. 2005;45:499-504.

Iber C, Ancoli-Israel S, Chesson A, Quan S, for the American Academy of Sleep Medicine. The AASM manual for the scoring of sleep and associated events; rules, terminology and technical specifications. 1st ed. Westchester, IL: American Academy of Sleep Medicine; 2007.

Imamura Y, Ando H, Ashihara T, Fukuyama T. Myocardial adrenergic nervous activity is intensified in patients with heart failure without left ventricular volume or pressure overload. $\mathrm{J}$ Am Coll Cardiol. 1996;28:371-5.

Jennum P, Ibsen R, Knudsen S, Kjellberg J. Comorbidity and mortality of narcolepsy: a controlled retro- and prospective national study. Sleep. 2013;36:835-40.

Kayaba Y, Nakamura A, Kasuya Y, Ohuchi T, Yanagisawa M, Komuro I, et al. Attenuated defense response and low basal blood pressure in orexin knockout mice. Am J Physiol Regul Integr Comp Physiol. 2003;285:R581-593.

Lo Martire V, Silvani A, Bastianini S, Berteotti C, Zoccoli G. Effects of ambient temperature on sleep and cardiovascular regulation in mice: the role of hypocretin/orexin neurons. PloS One. 2012;7:e47032.

Lorenzo C, Williams K, Hunt KJ, Haffner SM. The National Cholesterol Education Program Adult Treatment Panel III, International Diabetes Federation, and World Health Organization definitions of the metabolic syndrome as predictors of incident cardiovascular disease and diabetes. Diabetes Care. 2007;30:8-13.

Merlet P, Valette H, Dubois-Randé JL, Moyse D, Duboc D, Dove P, et al. Prognostic value of cardiac metaiodobenzylguanidine imaging in patients with heart failure. J Nucl Med Off Publ Soc Nucl Med. 1992;33:471-7.

Miyamoto T, Miyamoto M, Inoue Y, Usui Y, Suzuki K, Hirata K. Reduced cardiac 123IMIBG scintigraphy in idiopathic REM sleep behavior disorder. Neurology. 2006;67:2236-8. Montplaisir J, Gagnon J-F, Fantini ML, Postuma RB, Dauvilliers Y, Desautels A, et al. Polysomnographic diagnosis of idiopathic REM sleep behavior disorder. Mov Disord Off $\mathbf{J}$ Mov Disord Soc. 2010;25:2044-51.

Nakajima K, Okuda K, Matsuo S, Wakabayashi H, Kinuya S. Is 123Imetaiodobenzylguanidine heart-to-mediastinum ratio dependent on age? From Japanese Society of Nuclear Medicine normal database. Ann Nucl Med. 2018;32:175-81.

Nakata T, Miyamoto K, Doi A, Sasao H, Wakabayashi T, Kobayashi H, et al. Cardiac death prediction and impaired cardiac sympathetic innervation assessed by MIBG in patients with failing and nonfailing hearts. J Nucl Cardiol Off Publ Am Soc Nucl Cardiol. 1998;5:579-90. Ohayon MM. Narcolepsy is complicated by high medical and psychiatric comorbidities: a comparison with the general population. Sleep Med. 2013;14:488-92.

Plazzi G, Moghadam KK, Maggi LS, Donadio V, Vetrugno R, Liguori R, et al. Autonomic disturbances in narcolepsy. Sleep Med Rev. 2011;15:187-96.

Samson WK, Gosnell B, Chang JK, Resch ZT, Murphy TC. Cardiovascular regulatory actions 
of the hypocretins in brain. Brain Res. 1999;831:248-53.

Shirasaka T, Nakazato M, Matsukura S, Takasaki M, Kannan H. Sympathetic and cardiovascular actions of orexins in conscious rats. Am J Physiol. 1999;277:R1780-1785. Silvani A, Bastianini S, Berteotti C, Cenacchi G, Leone O, Lo Martire V, et al. Sleep and cardiovascular phenotype in middle-aged hypocretin-deficient narcoleptic mice. J Sleep Res. 2014;23:98-106.

Sisson JC, Wieland DM, Sherman P, Mangner TJ, Tobes MC, Jacques S.

Metaiodobenzylguanidine as an index of the adrenergic nervous system integrity and function. J Nucl Med. 1987;28:1620-1624.

Sorensen GL, Knudsen S, Petersen ER, Kempfner J, Gammeltoft S, Sorensen HBD, et al. Attenuated heart rate response is associated with hypocretin deficiency in patients with narcolepsy. Sleep. 2013;36:91-98.

Yamada T, Shimonagata T, Fukunami M, Kumagai K, Ogita H, Hirata A, et al. Comparison of the prognostic value of cardiac iodine-123 metaiodobenzylguanidine imaging and heart rate variability in patients with chronic heart failure: a prospective study. J Am Coll Cardiol. $2003 ; 41: 231-8$.

Yamashina S, Yamazaki J. Neuronal imaging using SPECT. Eur J Nucl Med Mol Imaging. 2007;34:939-50.

Zhang W, Sakurai T, Fukuda Y, Kuwaki T. Orexin neuron-mediated skeletal muscle vasodilation and shift of baroreflex during defense response in mice. Am J Physiol-Regul Integr Comp Physiol. 2006;290:R1654-R1663. 
Table $1 .{ }^{123}$ I-MIBG cardiac scintigraphy results in patients with narcolepsy type 1 (NT1) and controls.

\begin{tabular}{|c|c|c|c|c|c|c|c|}
\hline & \multicolumn{2}{|c|}{$\begin{array}{c}\text { Controls } \\
n=91\end{array}$} & \multicolumn{2}{|c|}{$\begin{array}{l}N T 1 \\
n=56\end{array}$} & \multirow{2}{*}{$\begin{array}{l}\text { Model } 0^{(3)} \\
p \text {-value }\end{array}$} & \multirow{2}{*}{$\begin{array}{l}\text { Model } 1^{(4)} \\
p \text {-value }\end{array}$} & \multirow{2}{*}{$\begin{array}{l}\text { Model } 2^{(5)} \\
p \text {-value }\end{array}$} \\
\hline & $n$ & $\%$ & $n$ & $\%$ & & & \\
\hline Sex (men) & 42 & 46.15 & 38 & 67.86 & 0.01 & & \\
\hline Age, years ${ }^{(1)}$ & 53.0 & $0 ; 87.00)$ & 38. & $00 ; 86.00)$ & 0.02 & & \\
\hline \multicolumn{8}{|l|}{ Age, years } \\
\hline$<38$ & 20 & 21.98 & 26 & 46.43 & 0.007 & & \\
\hline$[38-61[$ & 38 & 41.76 & 13 & 23.21 & & & \\
\hline$\geq 61$ & 33 & 36.26 & 17 & 30.36 & & & \\
\hline Body mass index, $\mathrm{kg} / \mathrm{m}^{2}$ & 24.9 & $0 ; 37.00)$ & 26.6 & $00 ; 47.80)$ & 0.10 & & \\
\hline Delayed heart/mediastinum ratio ${ }^{(l)}$ & 1.70 & 2.65) & 1.7 & ;2.29) & 0.62 & 0.62 & 0.54 \\
\hline \multicolumn{8}{|l|}{ Delayed heart/mediastinum ratio ${ }^{(2)}$} \\
\hline$\leq 1.61$ & 31 & 34.07 & 17 & 30.36 & 0.66 & 0.87 & 0.39 \\
\hline ]1.61-1.82] & 31 & 34.07 & 17 & 30.36 & & & \\
\hline$>1.82$ & 29 & 31.87 & 22 & 39.29 & & & \\
\hline $\begin{array}{l}{ }^{(1)} \text { Continuous variables ar } \\
{ }^{(2)} \text { Tertiles for the whole st } \\
{ }^{(3)} \text { Model 0: crude associat } \\
{ }^{(4)} \text { Model 1: adjustment for } \\
{ }^{(5)} \text { Model 2: adjustment for }\end{array}$ & $\begin{array}{l}\text { expre } \\
\text { dy po } \\
\text { ns } \\
\text { age, s } \\
\text { age, s }\end{array}$ & $\begin{array}{l}\text { s median } \\
\text { on (NT1 }\end{array}$ & $\begin{array}{l}{[\mathrm{min}} \\
\mathrm{d} \mathrm{co}\end{array}$ & value-ma & imum valu & & \\
\hline
\end{tabular}


Table 2. Clinical and neurophysiological determinants of low heart/mediastinum ratio $(<1.62)$ in patients with narcolepsy type 1 (NT1).

\begin{tabular}{|c|c|c|c|c|c|}
\hline \multicolumn{6}{|c|}{ Delayed heart/mediastinum ratio } \\
\hline & & $\begin{array}{c}<1.62^{*} \\
\mathrm{n}=18\end{array}$ & $\begin{array}{l}\geq 1.62 \\
n=38\end{array}$ & Model 0 ${ }^{(3)}$ & Model $1^{(4)}$ \\
\hline Variable & $n$ & $\%$ & $\%$ & p-value & p-value \\
\hline \multicolumn{6}{|c|}{ Clinical characteristics and biological results } \\
\hline Sex (men) & 12 & 66.67 & $26 \quad 68.42$ & 0.90 & 0.54 \\
\hline Age, years ${ }^{(1)}$ & & $50(19.00 ; 84.00)$ & $32.50(13.00 ; 86.00)$ & 0.005 & - \\
\hline Body mass index, $\mathrm{kg} / \mathrm{m}^{2(l)}$ & & $50(22.50 ; 47.80)$ & $26.00(17.00 ; 43.40)$ & 0.01 & 0.02 \\
\hline \multicolumn{6}{|l|}{ Body mass index, $\mathrm{kg} / \mathrm{m}^{2}$} \\
\hline$<25$ & 1 & 5.56 & $15 \quad 39.47$ & 0.007 & 0.01 \\
\hline$[25-30[$ & 9 & 50.00 & $20 \quad 52.63$ & & \\
\hline$\geq 30$ & 8 & 44.44 & 37.89 & & \\
\hline $\begin{array}{l}\text { Treatment for NT1 at time of scintigraphy } \\
\text { (yes) }\end{array}$ & 10 & 55.56 & $6 \quad 15.79$ & 0.004 & 0.26 \\
\hline ESS score ${ }^{(l)}$ & 18.00 & $(14.00 ; 24.00)$ & $19.00(7.00 ; 23.00)$ & 0.62 & 0.32 \\
\hline RBD, clinically defined (yes) & 14 & 77.78 & $20 \quad 52.63$ & 0.08 & 0.28 \\
\hline Age at EDS onset, years ${ }^{(1)}$ & & $0(14.00 ; 45.00)$ & $18.00(10.00 ; 48.00)$ & 0.13 & 0.85 \\
\hline CSF hypocretin-1 level, $p g / m l^{(1)}$ & & $0(0.00 ; 71.00)$ & $16.00(0.00 ; 104.00)$ & 0.45 & 0.17 \\
\hline \multicolumn{6}{|c|}{ Cardiovascular risk factors and comorbidities } \\
\hline Regular alcohol use (yes) & 9 & 50.00 & $20 \quad 52.63$ & 0.85 & 0.91 \\
\hline Regular tobacco use (yes) & 9 & 50.00 & $18 \quad 47.37$ & 0.85 & 0.53 \\
\hline Physical inactivity (yes) & 10 & 55.56 & $18 \quad 47.37$ & 0.57 & 0.88 \\
\hline Metabolic syndrome (yes) & 5 & 27.78 & $\begin{array}{ll}0 & 0.00\end{array}$ & NA & NA \\
\hline Cardiovascular comorbidities (yes) ${ }^{(2)}$ & 14 & 77.78 & 1128.95 & 0.001 & 0.03 \\
\hline - $\quad$ Diabetes mellitus type 2 (yes) & 1 & 5.56 & $0 \quad 0.00$ & NA & NA \\
\hline - $\quad$ Cardiac disorders (yes) & 4 & 22.22 & $5 \quad 13.16$ & 0.39 & 0.37 \\
\hline - Hypertension (yes) & 9 & 50.00 & $6 \quad 15.79$ & 0.01 & 0.49 \\
\hline - Dyslipidaemia (yes) & 9 & 50.00 & $8 \quad 21.05$ & 0.03 & 0.09 \\
\hline \multicolumn{6}{|c|}{ Ambulatory blood pressure monitoring } \\
\hline \multicolumn{6}{|l|}{ 24-hour measures } \\
\hline Mean 24 h systolic BP, $\mathrm{mmHg}^{(1)}$ & 131. & $0(105.00 ; 153.00)$ & $121.00(102.00 ; 164.00)$ & 0.03 & 0.81 \\
\hline Mean $24 \mathrm{~h}$ diastolic $\mathrm{BP}, \mathrm{mmHg}^{(1)}$ & 81. & $0(67.00 ; 122.00)$ & $71.00(55.00 ; 98.00)$ & 0.008 & 0.24 \\
\hline \multicolumn{6}{|l|}{ Daytime measures } \\
\hline Daytime systolic BP, mmHg ${ }^{(l)}$ & 133. & $0(106.00 ; 158.00)$ & $122.00(106.00 ; 171.00)$ & 0.04 & 0.91 \\
\hline
\end{tabular}




\section{Night-time measures}

\begin{tabular}{|c|c|c|c|c|}
\hline Night-time systolic BP, mmHg ${ }^{(l)}$ & $124.50(97.00 ; 160.00)$ & $113.00(90.00 ; 145.00)$ & 0.02 & 0.52 \\
\hline Night-time diastolic BP, $\mathrm{mmHg}^{(1)}$ & $75.00(53.00 ; 113.00)$ & $64.00(51.00 ; 89.00)$ & 0.006 & 0.21 \\
\hline \multicolumn{5}{|c|}{ Polysomnography results } \\
\hline Total sleep time, minutes ${ }^{(1)}$ & $366.50(186.00 ; 481.00)$ & $421.00(164.00 ; 522.00)$ & 0.05 & 0.76 \\
\hline Night sleep latency, minutes ${ }^{(1)}$ & $4.50(0.00 ; 22.00)$ & $3.50(0.00 ; 38.00)$ & 0.79 & 0.72 \\
\hline Night REM sleep latency, minutes ${ }^{(l)}$ & $28.50(0.00 ; 288.00)$ & $6.50(0.00 ; 328.00)$ & 0.76 & 0.26 \\
\hline Sleep efficiency, $\%^{(1)}$ & $76.47(43.07 ; 90.93)$ & $83.74(35.61 ; 95.55)$ & 0.04 & 0.68 \\
\hline Stage $1, \%^{(1)}$ & $14.15(4.16 ; 27.96)$ & $9.16(2.42 ; 34.14)$ & 0.07 & 0.46 \\
\hline Stage $2, \%^{(1)}$ & $46.74(30.20 ; 78.05)$ & $47.64(27.97 ; 62.03)$ & 0.23 & 0.53 \\
\hline Stage $3, \%^{(1)}$ & $14.05(0.00 ; 28.70)$ & $17.64(2.74 ; 38.19)$ & 0.08 & 0.49 \\
\hline REM sleep, $\%^{(1)}$ & $21.22(1.81 ; 37.62)$ & $23.70(6.96 ; 54.67)$ & 0.21 & 0.53 \\
\hline AHI, /hour ${ }^{(1)}$ & $15.56(0.50 ; 59.39)$ & $5.15(0.00 ; 60.00)$ & 0.04 & 0.59 \\
\hline Mean $\mathrm{SaO}_{2}, \%^{(1)}$ & $94.50(87.00 ; 98.00)$ & $95.00(91.00 ; 98.00)$ & 0.10 & 0.48 \\
\hline PLMS index, /hour ${ }^{(l)}$ & $15.91(0.13 ; 161.89)$ & $5.28(0.00 ; 138.59)$ & 0.07 & 0.44 \\
\hline Microarousal index, $/$ hour $^{(1)}$ & $25.30(3.30 ; 68.57)$ & $15.02(2.64 ; 42.50)$ & 0.01 & 0.02 \\
\hline Microarousal index in REM sleep, /hour ${ }^{(1)}$ & $17.81(0.00 ; 86.40)$ & $15.11(1.04 ; 54.61)$ & 0.14 & 0.14 \\
\hline Phasic EMG activity in REM sleep, $\%^{(1)}$ & $9.15(4.09 ; 27.50)$ & $4.07(0.60 ; 31.67)$ & 0.09 & 0.39 \\
\hline Tonic EMG activity in REM sleep, $\%^{(1)}$ & $19.15(1.20 ; 94.00)$ & $2.95(0.00 ; 96.43)$ & 0.06 & 0.26 \\
\hline $\begin{array}{l}\text { Phasic }(\geq 15 \%) \text { or } \\
\text { Tonic EMG activity ( } \geq 30 \%) \text { (yes) }\end{array}$ & 38.89 & 13.16 & 0.04 & 0.13 \\
\hline
\end{tabular}

${ }^{(1)}$ Continuous variables are expressed as medians [minimum value-maximum value]

(2) Cardiovascular comorbidities: diabetes type 2 or use of antidiabetic drugs, cardiac disorders (history of coronary artery disease, chronic heart failure, arrhythmia), hypertension or treatment with antihypertensive drugs, dyslipidaemia or treatment with lipid-lowering drugs, history of stroke.

${ }^{(3)}$ Model 0: crude association

${ }^{(4)}$ Model 1: adjustment for age

* Lowest tertile for the population with NT1

Abbreviations: $A H I=$ apnoea-hypopnea index, $B P=$ Blood pressure, $C S F$, cerebrospinal, EMG = electromyography, EDS = excessive daytime sleepiness, ESS = Epworth sleepiness scale, $N A=$ Test non applicable, $N T 1=$ narcolepsy type 1, PLMS = periodic leg movements during sleep, $P S G=$ polysomnography, $R B D=$ REM sleep behaviour disorder, $R E M$ sleep = rapid eye movement sleep, $\mathrm{SaO}_{2}$, oxygen saturation. 
Table 3. Clinical and neurophysiological determinants of low heart/mediastinum ratio in drug-free patients with narcolepsy type 1 (NT1) at the time of the MIBG scintigraphy.

\begin{tabular}{|c|c|c|c|c|c|}
\hline & \multicolumn{4}{|c|}{ Delayed heart/mediastinum ratio } & \multirow[b]{4}{*}{$p$-value } \\
\hline \multirow[b]{3}{*}{ Variable } & \multirow{2}{*}{\multicolumn{2}{|c|}{$\begin{array}{c}<1.62 \\
n=8\end{array}$}} & \multirow{2}{*}{\multicolumn{2}{|c|}{$\begin{array}{l}\geq 1.62 \\
n=32\end{array}$}} & \\
\hline & & & & & \\
\hline & $n$ & $\%$ & $n$ & $\%$ & \\
\hline \multicolumn{6}{|c|}{ Clinical characteristics and biological results } \\
\hline Sex (men) & 4 & 50.00 & 10 & 31.25 & 0.42 \\
\hline Age, years ${ }^{(1)}$ & \multicolumn{2}{|c|}{$36.50(19.00 ; 82.00)$} & \multicolumn{2}{|c|}{$28.50(13.00 ; 71.00)$} & 0.15 \\
\hline Body mass index, $\mathrm{kg} / \mathrm{m}^{2(l)}$ & \multicolumn{2}{|c|}{$29.03(22.50 ; 35.00)$} & \multicolumn{2}{|c|}{$26.05(17.00 ; 43.40)$} & 0.06 \\
\hline ESS score $^{(l)}$ & \multicolumn{2}{|c|}{$19.00(14.00 ; 22.00)$} & \multicolumn{2}{|c|}{$19.00(9.00 ; 23.00)$} & 0.50 \\
\hline RBD, clinically defined (yes) & 5 & 62.50 & 16 & 50.00 & 0.70 \\
\hline Age at EDS onset, years ${ }^{(1)}$ & \multicolumn{2}{|c|}{$20.00(14.00 ; 32.00)$} & \multicolumn{2}{|c|}{$18.00(10.00 ; 45.00)$} & 0.37 \\
\hline CSF hypocretin-1 level, $p g / m l^{(l)}$ & \multicolumn{2}{|c|}{$5.00(0.00 ; 38.00)$} & \multicolumn{2}{|c|}{$14.53(0.00 ; 104.00)$} & 0.51 \\
\hline \multicolumn{6}{|c|}{ Cardiovascular risk factors and comorbidities } \\
\hline Regular alcohol use (yes) & 4 & 50.00 & 17 & 53.13 & 0.99 \\
\hline Regular tobacco use (yes) & 5 & 62.50 & 16 & 50.00 & 0.70 \\
\hline Physical inactivity (yes) & 4 & 50.00 & 15 & 46.88 & 0.99 \\
\hline Metabolic syndrome (yes) & 1 & 12.50 & 0 & 0.00 & 0.20 \\
\hline Comorbidities (yes) $^{(2)}$ & 5 & 62.50 & 7 & 21.88 & 0.04 \\
\hline - Diabetes mellitus type 2 (yes) & 0 & 0.00 & 0 & 0.00 & NA \\
\hline - $\quad$ Cardiac disorders (yes) & 1 & 12.50 & 2 & 6.25 & 0.50 \\
\hline - Hypertension (yes) & 1 & 12.50 & 2 & 6.25 & 0.50 \\
\hline - Dyslipidaemia (yes) & 5 & 62.50 & 6 & 18.75 & 0.02 \\
\hline \multicolumn{6}{|c|}{ Ambulatory blood pressure monitoring } \\
\hline
\end{tabular}

\section{4-hour measures}

\begin{tabular}{|c|c|c|c|}
\hline Mean 24 h systolic $\mathrm{BP}, \mathrm{mmHg}{ }^{(1)}$ & $120.50(105.00 ; 129.00)$ & $120.00(103.00 ; 164.00)$ & 0.73 \\
\hline Mean 24 h diastolic BP, $\mathrm{mmHg}^{(1)}$ & $76.00(67.00 ; 85.00)$ & $70.00(55.00 ; 98.00)$ & 0.25 \\
\hline \multicolumn{4}{|c|}{ Polysomnography results } \\
\hline Total sleep time, minutes ${ }^{(l)}$ & $411.50(346.00 ; 481.00)$ & $439.50(264.00 ; 522.00)$ & 0.93 \\
\hline Night sleep latency, minutes ${ }^{(1)}$ & $3.00(0.00 ; 5.00)$ & $3.00(0.00 ; 31.00)$ & 0.65 \\
\hline Night REM sleep latency, minutes ${ }^{(1)}$ & $1.50(0.00 ; 163.00)$ & $5.00(0.00 ; 255.00)$ & 0.36 \\
\hline Sleep efficiency, $\%^{(1)}$ & $79.25(75.83 ; 90.93)$ & $83.74(58.93 ; 95.55)$ & 0.44 \\
\hline AHI, /hour ${ }^{(1)}$ & $8.95(0.50 ; 59.39)$ & $4.60(0.00 ; 29.70)$ & 0.33 \\
\hline
\end{tabular}




\begin{tabular}{|c|c|c|c|}
\hline PLMS index, /hour ${ }^{(l)}$ & $12.87(0.13 ; 161.89)$ & $4.95(0.00 ; 60.49)$ & 0.54 \\
\hline Microarousal index, /hour ${ }^{(1)}$ & $31.15(12.30 ; 68.57)$ & $14.95(2.64 ; 42.50)$ & 0.005 \\
\hline Microarousal index in REM sleep, /hour ${ }^{(l)}$ & $25.80(5.66 ; 71.25)$ & $16.36(1.04 ; 54.61)$ & 0.20 \\
\hline Phasic EMG activity in REM sleep, $\%^{(1)}$ & $8.50(4.30 ; 24.50)$ & $3.85(0.60 ; 20.90)$ & 0.008 \\
\hline Tonic EMG activity in REM sleep, $\%^{(l)}$ & $15.32(1.70 ; 38.90)$ & $2.15(0.00 ; 36.00)$ & 0.007 \\
\hline $\begin{array}{l}\text { Phasic }(\geq 15 \%) \text { or } \\
\text { Tonic EMG activity ( } \geq 30 \%) \text {, (yes) }\end{array}$ & 37.50 & 6.25 & 0.05 \\
\hline
\end{tabular}

${ }^{(1)}$ Continuous variables are expressed as medians [minimum value-maximum value]

(2) Cardiovascular comorbidities: diabetes type 2 or use of antidiabetic drugs, cardiac disorders (history of coronary artery disease, chronic heart failure, arrhythmia), hypertension or treatment with antihypertensive drugs, dyslipidaemia or treatment with lipid-lowering drugs, history of stroke.

Abbreviations: $A H I=$ apnoea-hypopnea index, $B P=$ Blood pressure, $C S F$, cerebrospinal fluid, $E M G$ = electromyography, EDS = excessive daytime sleepiness, $E S S=$ Epworth sleepiness scale, $N A=$ Test non applicable, $N T 1=$ narcolepsy type $1, P L M S$ = periodic leg movements during sleep, $P S G=$ polysomnography, $R B D=$ REM sleep behaviour disorder, REM sleep = rapid eye movement sleep, $\mathrm{SaO}_{2}$, oxygen saturation. 